\title{
NALGUM LUGAR ENTRE O EXPERIMENTALISMO E A \\ CANÇÃO POPULAR: AS CARTAS DE PAULO LEMINSKI A RÉGIS BONVICINO
}

Marcelo Sandmann*

\section{A nova edição das cartas de Leminski a Bonvicino}

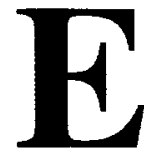

nvie meu dicionário: cartas e alguma crítica ${ }^{1}$ é a nova edição da correspondência enviada por Paulo Leminski ao poeta e amigo Régis Bonvicino entre 1976 e 1981 . Originalmente publicadas sob o título Uma carta uma brasa através (Iluminuras, 1992), as cartas voltam a circular neste ano de 1999, agora sob a chancela da Editora 34, dez anos portanto após o desaparecimento do poeta (7 de junho de 1989).

* Universidade Federal do Paraná.

I LEMINSKI, Paulo. Envie meu dicionário: cartas e alguma crítica / Paulo Leminski e Régis Bonvicino. Organização de Régis Bonvicino, com a colaboração de Tarso M. de Melo. São Paulo: Ed. 34, 1999. Diversos trechos das cartas serão transcritos ao longo deste estudo. Para facilitar a indicação bibliográfica, serão indicados apenas o número da carta em questão e a página em que ela aparece no referido volume. 
SANDMANN, M. Nalgum lugar entre o experimentalismo...

Algumas diferenças dignas de nota, e que terão contribuído para a mudança do título do volume, se fazem notar entre as duas edições.

Em primeiro lugar, trata-se agora de uma edição completa das cartas redigidas por Paulo Leminski. Organizada novamente por Régis Bonvicino, desta vez com a colaboração de Tarso M. de Mclo, esta edição apresenta um total de 68 cartas, cronologicamente ordenadas, devidamente numeradas e com muitas notas explicativas $\mathrm{em}$ anexo.

Em segundo lugar, as cartas encontram-se reproduzidas em fac-símile. $O$ leitor tem acesso direto às peculiaridades gráficas de todo o material. Leminski escrevia sempre a máquina, mas recorrentemente acrescentava ao texto observações manuscritas, desenhos e outros grafismos. Procedimentos característicos da poesia contaminam a correspondência, como o corte das linhas como se se tratasse de versos, a distribuição de palavras no branco da página, o uso expressivo da pontuação (quando não a sua simples supressão), entre outros jogos gráficos. $^{2}$

Finalmente, esta edição acrescenta novo material crítico ao material apresentado anteriormente como complemento. Se a primeira trazia textos de Régis Bonvicino, Carlos Ávila e Boris Schnaiderman sobre a obra do escritor curitibano, além de uma apresentação ao volume assinada por Cactano Veloso, esta vem acrescida de novos textos do próprio Régis Bonvicino, apresentação de Júlio Castañon Guimarães, nota biográfica de Tarso M. de Melo e uma bibliografia geral dos livros de Leminski, incluídas as suas traduções da obra de outros escritores. Trata-se, portanto, de uma boa introdução ao universo do poeta.

\section{Entre 1976 e 1981}

As cartas abrangem um período significativo da trajetória de Paulo Leminski e testemunham alguns dos dilemas da sua criação.

2 Nas transcrições de passagens das cartas, procurou-se não trair de todo suas peculiaridades gráficas. Como em muitas delas Leminski escreve como se tratasse de versos, com cortes nas linhas antes que estas cheguem à margem direita da página, as transcriçôes foram feitas tendo-se em vista o procedimento padronizado para citação de segmentos de um poema no corpo de um texto em prosa, ou seja, utilizando-se uma barra transversal para separar um verso do outro e duas barras quando se tratar de estrofes. 
SANDMANN, M. Nalgum lugar entre o experimentalismo...

Leminski estreara nacionalmente como poeta nas páginas de Invenção, publicação vinculada ao movimento concretista, com poemas incluídos nos números 4 (1964) e 5 (1966/67) da revista. Somente em 1975, no ano que antecede ao início da correspondência com Régis Bonvicino, é que viria a público o seu primeiro livro, o Catatau, longamente gestado desde pelo menos 1966 e saudado pelos seus entusiastas como um legítimo descendente da prosa experimental de James Joyce e escritores afins.

É sob as asas do concretismo e dentro da categoria da experimentação literária que se vai abrigar a produção inicial do escritor curitibano. Em relação ao movimento concreto, para além das afinidades poéticas existentes, convém não se perder de perspectiva o que o acolhimento por parte de poetas um pouco mais velhos, com prestígio em crescimento e sediados num grande centro como São Paulo poderia significar para um autor mais jovem e situado num meio artisticamente deslocado como Curitiba.

$\mathrm{A}$ interlocução com os poetas concretos e com outros autores que àquela altura se encontravam mais ou menos dentro do campo de imantação do concretismo é um dos temas centrais das cartas. Elas revelam o franco reconhecimento dessa influência e o desejo vital de independência em relação a ela.

O Leminski desses anos, como tantos outros autores, está às voltas com a herança concretista e com a tentativa de superação desse legado. A experiência da contracultura e, na sua esteira, a opção por uma poesia que viria aproximar de forma mais radical arte e vida, serão os ingredientes perturbadores de todo um universo de referências. $O$ investimento no coloquial, no espontâneo, no improviso, o aproveitamento mais direto dos conteúdos da própria existência individual como matéria de poesia vão armar um embate tenso com o construtivismo anti-subjetivo e formalista do concretismo mais ortodoxo.

Entre os anos de abrangência das cartas, vêm a público os primeiros livros individuais de poemas de Leminski, todos eles, como o Catatau, por intermédio de editoras curitibanas de irradiação muito restrita: Quarenta clics em Curitiba (Etecetera, 1976), não fosse isso e era menos / não fosse tanto e era quase (ZAP, 1980) e Polonaises (Ed. do autor, 1980). Será somente no início da década de 80 , com a publicação de Caprichos e relaxos (1983), que a sua poesia irá chegar a um público mais amplo, agora por intermédio de uma editora do porte da Brasiliense. Pela Brasiliense sairiam até o ano da sua morte diversas obras traduzidas, biografias, um romance e outro livro de poemas, Distraídos venceremos (1987).

As cartas evidenciam ainda o papel que a canção popular vai ocupar no seu universo de criação, quer como influência sobre a própria produção poética, quer como alternativa à poesia publicada em livro. Caetano Veloso, Gilberto 
SANDMANN. M. Nalgum lugar entre o experimentalismo...

Gil, Jorge Mautner, Jards Macalé, Tom Zé, Walter Franco são alguns dos nomes referidos. A visita de alguns destes artistas à casa de Leminski quando de passagem pela cidade, que as cartas documentam, é, além da amizade pessoal, testemunho do reconhecimento do poeta curitibano fora dos limites locais e da própria literatura. É evidente o entusiasmo com que Leminski noticia a Régis a boa acolhida por parte de Caetano ou Gil, por exemplo, às suas composições. Em 1981, Caetano Veloso iria gravar "Verdura" no disco Outras palavras, difundindo o poeta na cena musical brasileira e projetando-o para um público mais amplo.

Estas cartas escritas entre 1976 e 1981 registram um drama intelectual significativo, que ultrapassa seu próprio protagonista e vem reverberar com intensidade nos dias de hoje ainda. Leminski falou para o país a partir de um centro urbano periférico, defrontou-se com uma geração anterior de posições vigorosas e de prestígio, procurou cruzar a fronteira entre o livro e o disco (meios diferentes, a despeito das possíveis intersecções de linguagem, com públicos, amplitudes e respostas igualmente distintos). Seria oportuno seguir mais de perto o modo como ele mesmo formulou para si e para um companheiro de geração todas essas questões.

\section{A transmissão da lâmpada}

Como já ficou indicado, Paulo Leminski estreou nacionalmente como poeta nas páginas do n. $^{\circ} 4$ da revista Invenção, publicação do grupo concretista paulista, no ano de 1964. Convém lembrar que este movimento, lançado oficialmente em dezembro de 1956 na "Exposição Nacional de Arte Concreta", levada a público no Museu de Arte Moderna de São Paulo, se impôs no cenário da poesia brasileira, entre outros motivos, pela militância polêmica dos seus participantes, especialmente Augusto de Campos, Haroldo de Campos e Décio Pignatari, que redigiram manifestos, organizaram revistas, encontros de poesia c estabeleceram toda uma rede de interlocução com poetas mais velhos $e$ contemporâneos, inclusive autores estrangeiros importantes (Ezra Pound, E. E.Cummings, Eugen Gomringer, para citar alguns). ${ }^{3}$

3 Ensaio, manifestos, bem como uma sinopse do movimento concretista podem ser encontrados em CAMPOS, Augusto et al. Teoria da poesia concreta. 3. cd. São Paulo: Brasiliense, 1987. 
SANDMANN, M. Nalgum lugar entre o experimentalismo...

Nomes que se agregaram ao movimento na primeira hora, como Ferreira Gullar e Reinaldo Jardim, por exemplo, iriam romper com o núcleo paulista para organizar, em 1958/59, junto com artistas plásticos do Rio de Janeiro, o neo-concretismo. Ao longo dos anos 60 , outros movimentos de experimentação surgirão, entre eles o da poesia práxis, liderado por Mário Chamie. Adesões e dissidências geravam toda uma dinâmica complexa nos bastidores do texto literário, em que afetos e desafetos se explicitam e se acirram. Nas cartas de Leminski, redigidas já um bom tempo depois do momento em que a efervescência experimentalista, desdobramentos $\mathrm{e}$ as primeiras reações a ela vão se verificar, todo esse complexo ainda está muito vivo. A relação de Leminski e de outros poetas mais novos com esses diferentes agrupamentos não pode ser entendida apenas como uma opção poética stricto sensu.

Em relação ao concretismo, a situação de Leminski e de outros poctas da sua geração é apresentada com muita clareza na carta 8, datada de 9,10 e 11 de julho de 1977, uma das primeiras da correspondência.

Nesta carta, depois de comentar alguns poemas enviados por seu interlocutor, o escritor curitibano começa por aludir a um livro chinês intitulado $A$ transmissão da lâmpada, sobre a história dos quarenta e sete patriarcas zen, a começar do primeiro discípulo de Buda, Mahakasiapa. Na "transmissão da lâmpada", como esclarece o poeta, verifica-se a transmissão dos poderes de um patriarca a outro, numa linha ininterrupta de sucessão. ${ }^{5}$

Leminski rememora então um encontro com Décio Pignatari na casa do poeta Antônio Risério, em que aquele, apontando para Bonvicino, Risério, Pedro Tavares de Lima e o próprio Leminski, jovens autores ali presentes, teria dito: "é preciso acabar com o concretismo, e quem pode fazer isso são vocês." Esse momento é vivido como uma espécie de rito: "senti algo assim como A TRANSMISSÃO DA LÂMPADA". 6

4 Na carta 8, datada de 09/10/11 de julho de 1977, ao comentar poema enviado por Régis Bonvicino, Leminski, pejorativamente, vai dizer: "depois a disposição que v. deu parece coisa de praxista" (p. 42). Se aqui o juizo poderia parecer estritamente poético, vale a pena conferir outra passagem, agora da carta 38, de 11 de outubro de 1978, em que se explicita melhor o movimento dos bastidores: "vamos parar com essa coisinha campos de 'não mencione gullar q promove'./ 'não fale em não sei o q q não é tático'..." (p. 103-104) O "campos", com inicial em letra minúscula, são os irmāos Haroldo e Augusto de Campos.

5 No texto de apresentação à edição brasileira de Introdução ao zen-budismo, de D. T. Suzuki, Murillo Nunes de Azevedo refere-se aos Anais da difusão da lâmpada, redigidos em 1209 por Lin Tsoun Hsiu. (Cf. SUZUKI, D. T. Introdıçäo ao zen-budismo. Trad. por Murillo Nunes de Azevedo. São Paulo: Pensamento, [s/d.] p. 35).

6 Carta 8, p. 43. 
SANDMANN, M. Nalgum lugar entre o experimentalismo...

A analogia é curiosa. Leminski, cujo interesse pelo zen e pelo hai-kai são bastante conhecidos, transforma uma conversa entre jovens poetas e o veterano Pignatari numa espécie de ritual de iniciação, equivalente ao ritual de transmissão dos poderes de um patriarca zen ao seu sucessor. Vale a pena repisar que, no caso do zen-budismo, trata-se da manutenção de uma linha de continuidade e autoridade que supostamente viria desde o próprio Buda, fundador de uma religião e de seus muitos desdobramentos. Leminski reconhece a autoridade do poeta mais velho, do "patriarca" Pignatari, e vê a si próprio e aos colegas de geração como continuadores da prática poética por ele representada.

Mas a "lição" transmitida ("é preciso acabar com o concretismo") é sem dúvida contraditória. A expressão "transmissão da lâmpada" parece implicar necessariamente os sentidos de tradição e continuidade. Como continuar algo que, na própria formulação de Décio Pignatari, precisaria ser encerrado?

$\mathrm{O}$ legado concretista é problemático para os novos. $\mathrm{O}$ investimento a todo custo na renovação de códigos e na ruptura em relação ao status quo literário, fundamento da vanguarda, quando passado à geração seguinte como conquista, parece se voltar contra seus próprios defensores iniciais.

Continuar o concretismo significaria, paradoxalmente, encerrá-lo. Ou, numa formulação um pouco mais dialética do próprio Leminski na mesma carta, absorvê-lo para tentar superá-lo: "nós já estamos chegando lá/isto é/ em muitos momentos do nosso trabalho / às vezes mais às vezes menos / já consegui ver a fímbria de algo / q já não é mais concretismo / embora o pressuponha e o tenha deglutido". 8

O concretismo deixa marcas fortes na poesia brasileira não apenas pelo que há de revolucionário nas obras dos seus principais integrantes, mas também por ter mobilizado todo um arsenal teórico-crítico sofisticado para a defesa de suas posições. Ao zelo teórico do movimento, Leminski vai contrapor a práxis sem teoria: "acho que não devemos mais nos preocupar com palavras / afinal nós vamos chegar lá fazendo / e não falando".

Finalmente, traz à discussão o Catataı e o papel desta obra em sua trajetória: "passei muitos anos de olhos voltados para S. Paulo / para o grupo Noigandres / para Augusto, principalmente / escrevendo para eles / preocupado

7 Nas cartas, Leminski refere-se noutras ocasiões a Décio Pignatari, Augusto e Haroldo de Campos como "os patriarcas", termo que, conhecido o anarquismo iconoclasta de muitas de suas posições, acaba por se revestir de um misto de reverência e ironia.

8 Carta 8, p. 43.

9 Carta 8, p. 43. 
SANDMANN, M. Nalgum lugar entre o experimentalismo...

em saber O QUE ELES IAM ACHAR// nessa época eu era 'concretista' // mas eu era uma porção de outras coisas também / e quando eu deixei que elas agissem mais forte / fiz o Catatau".

Como avalia Leminski, o Catatau é um divisor de águas dentro da sua produção. Antes dele, o poeta estava em plena sintonia com o movimento, aceitava sem restrição o rótulo de "concretista". Depois dele (e com ele), novos ingredientes e preocupações vão surgir de modo mais evidente, deslocados já em relação às posições mais ortodoxas do movimento, a despeito do experimentalismo explícito desta obra. ${ }^{11}$

É dentro desta perspectiva que se poderia entender as reações mais ou menos reticientes de Décio, Haroldo e Augusto em relação ao livro na primeira hora. Como conta Lemisski, Décio Pignatari usara termo e expressões como "monolito" e "é uma boa" para caracterizá-lo. Haroldo, aliás, ainda não havia se pronunciado ("de Haroldo nunca ouvi nem uma palavra!). ${ }^{12}$ Mas é quando se refere a Augusto de Campos que as possíveis tensões vão se explicitar melhor: "tenho certeza que para o paladar weberniano-joãogilbertesco / de Augusto / o Catatau deve ter parecido bagunçado demais / irregular demais / entrópico demais", 13

Aqui, certamente, surge concentrado o elemento que, na perspectiva do poeta curitibano, estaria gerando a dissensão. Leminski vai agregar à sua

10 Carta 8, p. 44.

11 Na segunda ediçao do Catatau, saída a público em 1989, encontram-se dois breves tex tos de Leminski em que o escritor explicita como concebeu o livro e dá algumas pistas para quem quiser se aventurar em sua difícil leitura. Mais no final do mesmo volume, encontra-se uma pequena fortuna crítica. (LEMINSKI, Paulo). Calatau. 2. ed. Porto Alegre: Sulina, 1989). Em artigo recente, Tarso M. de Melo aborda diferentes aspectos de Catatau, contrapondo-o inclusive a outras obras de experimentação com as quais o livro de Leminski guarda afinidades, sem deixar de revelar grandes diferenças em relaçāo a elas ( MELO, Tarso de. Qualigrafeira. Vola de Cocho, abr./maio 1998).

12 Carta 8, p. 44. Haroldo de Campos iria dedicar, no final da década de 80, todo um ensaio de Catatau (Cf. CAMPOS, Haroldo de. Uma leminskíada barrocodélica). Folha de S. Paulo, 2 set. 1989).

13 Carta 8, p. 44. Para uma compreensão mais precisa da expressão "paladar weberniano-joãogilbertesco", $c f$. os ensajos de Augusto de Campos e outros autores sobre música no volume Balanço da bossa e outras bossas, em especial aqueles que tratam do compositor Anton Webern e das inovaçōes bossa-novísticas de João Gilberto. Insistentemente vai se chamar a atenção aí para o rigor construtivo das composiçōes de Webern e para as interpretações enxutas e precisas do violāo e da voz de João. De alguma forma, o poeta brasileiro evidencia nessas personalidades artísticas aparentemente tão distantes entre si aquilo que parece haver em comum entre suas realizaçōes e a sua (dele, Augusto de Campos) própria poética. (CAMPOS, Augusto. Balaņ̧o da bossa e outras bossas. 3. ed. São Paulo: Perspectiva, 1978.) 
SANDMANN, M. Nalgum lugar entre o experimentalismo...

experiência concretista um outro tipo de experiência com a linguagem, oriunda certamente de outras fontes de referência e de uma outra relação pessoal com o mundo. Ao final da carta, a palavra-chave para este tipo de experiência vai aparecer sem pejo: "sem abdicar dos rigores de linguagem / precisamos meter paixão em nossas constelações / paixão / PAIXÃO".

O termo é certamente problemático quando analisado de modo mais preciso. Em que medida uma palavra de semântica tão vaga e ampla como "paixão" poderia compor, por si só, o traço distintivo da poética de Leminski?

$\mathrm{Na}$ verdade, o que parece se explicitar ai é muito mais uma atitude diante da palavra poética e da vida do que qualquer outra coisa, atitude pretendida como estando em contraposição à atitude dos poetas paulistas. O poeta curitibano, em sintonia com outros jovens autores, está reagindo contra o controle racional excessivo, o construtivismo, o anti-subjetivismo, o decoro intelectual e erudito, entrevistos como elementos capitais da atitude concretista.

Numa carta posterior (carta 64, de 28 de março de 1980), Leminski vai recorrer à expressão "desregramento contracultural" para evidenciar o seu comportamento: "prefiro continuar agitando minha bandeira (mesmo sabendo-a com furos graves e sujeita a furacões), onde talvez a ênfase (o spotlight) não estcja em poesia, mas na vida, o desregramento contracultural, [...]". ${ }^{15} \mathrm{O}$ "desregramento contracultural" vai fazer com que o pêndulo se desloque da "poesia" em direção à "vida".

Não cabe aqui aprofundar um comentário sobre a oposição "arte x vida", que tem rendido desde sempre inesgotáveis discussões. No caso em questão, vale a pena sublinhar mais uma vez a opção vitalista de Leminski, tributária da experiência contracultural, como ele mesmo sublinha. A contracultura é certamente um dos elementos que mais fortemente vai distinguir sua trajetória da dos poetas experimentalistas da geração anterior. ${ }^{16}$

14 Carta 8, p. 45. A combinação do "rigor" com outro elemento que em certa medida entra em conflito com ele aparece outras vezes nas cartas. $C f$., por exemplo, a carta 9: "que a estátua da liberdade / e a estátua do rigor / velem por todos nós" (carta 9, p. 50). O título do primeiro livro de poemas pela Brasiliense recupera essa tensão: Caprichos e relaxos.

15 Carta 64, p.168.

16 Na sequiência da passagem transcrita acima, Leminski vai dizer: "o que eu gostaria, no fundo, talvez, é que as pessoas vivessem mais esculhambadamente, reinventando essas bobagens todas do viver cotidiano, um novo sexo, um novo ver, uma nova moral". Essas questões são recorrentes nas cartas. Como mais um exemplo, se poderia citar trechos da carta 10: "eu já te disse / PARA SER POETA / TEM QUE SER MAIS QUE POETA / v. tem que ser um monte de outras coisas mais / 
SANDMANN, M. Nalgum lugar entre o experimentalismo...

\section{Debelando interditos e tabus}

Na parte final da carta 8, uma frase de Leminski sintetiza bem a situação em que ele e outros se encontravam: "somos os últimos concretistas e os primeiros não sei o que lá". 17

Toda a carta, como se viu, parece glosar justamente este mote. Ao lado do claro desejo de buscar um caminho independente, percebe-se que Leminski refere-se aos poetas mais velhos de modo bastante reverente, reconhecendo a influência exercida sobre a sua própria produção e avaliando-a como positiva. De um modo geral, esse é o tom das cartas quando o assunto vem à baila.

No entanto, na carta 42, de 6 de novembro de 1978, pode-se ler algumas passagens em que a reação à presença da poesia concreta se faz de forma bem mais agressiva. Se não é propriamente uma ruptura definitiva com o movimento, é certamente um vigoroso desabafo.

De um modo geral, alguns dos ingredientes que aqui vão surgir para problematizar as opções dos poetas concretos têm visíveis colorações políticas. Já na primeira página da carta, isso francamente se revela: “o q a gente precisa é combater/debelar alguns interditos e tabus $q$ a poesia concreta instalou. $O$ fascismo (vindo de pound, v. queria o q?) da distinção entre inventors, masters e diluters, por ex. a raça pura, as raças inferiores... esteticismo de campo de konzentration... nesta ala, os inventors... aos fornos crematórios, os diluidores...". 18

Ezra Pound, nome central do paideuma concretista ${ }^{19}$, era um simpatizante do fascismo de Mussolini. Leminski, num gesto contrário ao dos poetas paulistas, não vai ver distinções entre as opções políticas de Pound c suas postulações poéticas (p. ex., a distinção fortemente hierarquizada entre "inventores", "mestres" e "diluidores"). ${ }^{20}$ Segundo ele, poética e política comporiam

senão donde? / v. vai acabar fazendo literatura de literatura //v. tem que esculhambar mais / pintar mais por fora das molduras / EXISTENCIALMENTE". (Carta 10, p. 52.) E mais adiante: "rompa // fique mais irregular // seja mais inconveniente // é a linguagem que está a serviço da vida / não a vida a serviço da linguagem". (Carta 10, p. 53)

17 Carta 8, p. 45.

18 Carta 42, p. 109.

19 Cf. "Plano-piloto para poesia concreta" (CAMPOS et al., Teoria...), onde os "precursores" do concretismo, entre eles Ezra Pound, surgem elencados. Para o conceito poundiano de paideuma, ver a nota 20 .

20 Cf. a esse respeito $A b c$ da literatura, de Ezra Pound, traduzido por Augusto de Campos 
SANDMANN, M. Nalgum lugar entre o experimentalismo...

um continuum. A vanguarda, como os totalitarismos políticos, é autoritária. Ela instaura tabus e interditos, hierarquiza, demoniza seus inimigos. A aproximação do "campo literário" aos "campos de concentração", a despeito do seu exagero, é uma imagem forte e índice claro do enclausuramento a que se via submetido o próprio Leminski.

A politização do debate estético surge ainda mais à frente, agora na oposição entre Ezra Pound e Vladimir Maiakóvski, outro poeta caro ao concretismo: "colocar pound, como vanguarda, ao lado de maiakovski, é uma gracinha esteticista. como se existisse (ilusão intelectual burguesa) um museu imaginário, onde as 'grandes obras do espirito' ficariam esperando por toda a eternidade que 'a Espécie humana' delas precisasse... pouco importando os pressupostos políticos, de classe, de luta, de que a obra fosse portadora... essa neutralidade não existe."21

Maiakóvski, alinhado com as posições libertárias da primeira hora da Revolução Russa, se situaria em franco antagonismo político em relação a Pound. Uma aproximação entre os dois, como a que se verifica no paideuma concreto, só seria possivel a partir de uma obliteração dos "pressupostos políticos, de classe, de luta" que, de alguma forma, estariam por detrás de suas obras, como que a condicionar os seus próprios significados. Desentranhar as obras do contexto em que foram geradas, avaliá-las segundo critérios restritamente formais e fixá-las num "museu imaginário" seria uma "ilusão intelectual burguesa", seria apostar numa "neutralidade" (política e social) inexistente nas obras.

Os questionamentos a que Leminski vai submeter a ortodoxia concretista desembocam em duas séries de problemas estreitamente vinculados que vão ser fundamentais para a sua própria poesia: a crítica da busca do novo a todo custo e o desejo de comunicação com o público.

Com relação ao primeiro ponto, lê-se o seguinte na carta 42: "a novidade a todo custo como um absoluto (uma obra vale pela inovação) não é a única coisa que se procura em arte. essa é a miragem dos concretistas. eu posso estar buscando outros valores, através de outras categorias de pensamento e apreciação..." A passagem é clara: o "novo" como critério de juízo estético é um

e José Paulo Paes. Na introdução ao volume, “As antenas de Ezra Pound”, Augusto de Campos sintetiza bem algumas das postulações fundamentais do poeta norte-americano, entre elas a distinção entre os diferentes tipos de criadores e co conceito de paideuma (POUND, Ezra. Abc da literatura. 5. ed. São Paulo: Cultrix, 1986).

21 Carta 42, p. 110. 
SANDMANN, M. Nalgum lugar entre o experimentalismo...

critério relativo, que depende da perspectiva adotada. Ao dizer isso, Leminski deixa claro que, para ele, que passou pelo concretismo e pela experimentação, outros critérios estariam surgindo nesse momento como determinantes.

Submetendo então o "novo" como critério a uma crítica de perfil sociológico, o poeta vai complementar mais adiante: "não resta dúvida q esse culto do novo em poesia de vanguarda está ligado ao "novo" que a publicidade usa... novo Omo, novo Rinso... novo... novo... mais novo... novo pra que? ou o novo não precisa se justificar? novo é novo, e tá acabado?"23 Ao aproximar abusca pelo novo em arte à dinâmica das mercadorias na sociedade de consumo, Leminski faz, implicitamente, uma crítica veemente à vanguarda. Mas a afirmação vai ser atenuada a seguir, quando a avaliação do "novo" surge um pouco mais nuançada e valores como "novidade" e "originalidade" são ainda preservados como positivos: "claro, existe uma preocupação com novidade em qualquer artista de verdade. com novidade, com originalidade, com voz própria. mas o novo custe o que custar me parece um mito, uma alienação."24

Toda essa crítica vai se concentrar finalmente numa crítica incisiva ao concretismo em si, numa passagem que começa a deixar clara a nova orientação do poeta: "a poesia concreta já proclamou-se a única boa e certa. A Nova! 'dando por encerrado...' / e se o povo todo gostar do verso, o que é que a gente faz? I expulsa o povo? / ou faz como a aveztruz, enfia a cabeça num ideograma da dinastia ming e faz de conta que ele não existe?" 25 Descontando o populismo meio ligeiro de todo o trecho, ele vale como testemunho da preocupação agora com a comunicação e com o público, elementos alheios ao aqui suposto elitismo da vanguarda.

A comunicação surge portanto como um critério importante: "quero fazer uma poesia que as pessoas entendam. / q não precise dar de brinde um tratado sobre Gestalt ou uma tese de jakobson sobre as estruturas subliminares dos anagramas paronomásticos..." ${ }^{26}$ É com ironia que o poeta vai se referir ao aparato teórico-crítico que costuma acompanhar a práxis poética concretista, fazendo de sua fruição algo restrito aos iniciados.

22 Carta 42, p. 110

23 Carta 42, p. 110.

24 Carta 42, p. 110.

25 Carta 42, p. 111. Há nesta passagem uma citação do "Plano-piloto para poesia concreta": "dando por encerrado o ciclo histórico do verso (unidade rítmico-formal), a poesia concreta começa por tomar conhecimento do espaço gráfico como agente estrutural." (Cf. CAMPOS, Augusto de et al. Teoria..., p. 156.

26 Carta 42, p. 111 
SANDMANN, M. Nalgum lugar entre o experimentalismo...

Essa pretendida ampliação de horizontes tem como pressuposto um tipo de engajamento social que não obedece a um vinculação política de todo explícita. Não se trata propriamente de um questionamento como aquele a que a esquerda tradicionalmente submeteu as vanguardas ao longo das décadas de 60 e 70, como se Leminski simplesmente tivesse mudado de partido após sua passagem pelo experimentalismo. O que transparece aqui, em grande medida, é novamente a dialética entre arte e vida, devida muito mais aos vínculos do poeta com a contracultura do que com a esquerda ortodoxa.

É nesse sentido, aliás, que se lêem algumas outras passagens da carta: "uma escolha de comunicação traz responsabilidades sociais, determina as linhas do produto, afeta o plano semântico. afinal, as pessoas não estão interessadas no que não lhes diz respeito, à vida, ao seu círculo de vida, aos seus interesses..."27 Mais adiante: "estou interessado agora em estruturar conteúdos. só me interessa o que tenho a dizer. e só me interessa dizer o q interessa a vários, a muitos. quero sentidos. / meus 5 e mais os de todos mundo." ${ }^{, 28}$ E finalmente: "é a poesia que está dentro da vida, não o contrário..."29

Ao final da carta, vamos encontrar os ingredientes que vêm agora se somar à experiência com o concretismo e com a prosa experimental, abrindo perspectivas de comunicação efetiva com o público: "tenho dois neutralizadores da literatura (2 anti-ambientes: / - música popular/composição / - publicidade/lay-out/arte". 30

27 Carta 42, p. 111.

28 Carta 42, p. 112.

29 Carta 42, p. 113.

30 Canta 42, p. 120. Estes dois "neutralizadores da literatura" apareciam, numa formulação um pouco distinta quanto ao segundo elemento, já na carta 8 anteriormente comentada: "a música popular é a escola / o cartum é a escola" (carta 8, p. 45). Trata-se de uma idéia obsessiva de Leminski, que, numa entrevista a Almir Feijó, em 1978, dizia o seguinte: “A associação entre poesia e música tende a se tornar cada vez maior em termos de Brasil. Os poetas mais bem dotados, mais talentosos vêm, pelo menos, prestando muita atenção na poesia dos letristas da música popular. E do outro lado é a coisa do cartun, quer dizer, a área plástica, a área visual onde também há uma visão curiosa. A poesia também está se manifestando sob a forma do cartun." (Cf. Paulo Leminski. Série Paranaenses, n. 2. Curitiba: Scientia et Labor, 1988. p. 28). 
SANDMANN, M. Nalgum lugar entre o experimentalismo...

\section{Os dois neutralizadores da literatura}

A formulação de Paulo Leminski acima transcrita é capital para o entendimento dos caminhos da sua poesia. As questões que ela levanta são muitas e, se analisadas com algum detalhe, bastante ricas.

Em primeiro lugar, seria bom frisar que a publicidade vai surgir como uma opção profissional para Leminski antes de tudo. Portanto, é com um passo atrás que se deve ler a equação que aproxima canção e publicidade e as confronta com poesia, como se tratasse simplesmentẹ de uma opção desinteressada por esta ou aquela linguagem.

Nos anos de abrangência das cartas, ainda sem vínculos com uma grande editora e na iminência de ver canções suas lançadas em disco por grandes nomes da música popular brasileira, a publicidade se impõe como alternativa de sobrevivência material. Em todo caso, Leminski extrai aspectos positivos da experiência de submeter o trabalho com a linguagem às exigências do mercado de bens de consumo. ${ }^{31}$

Sem tocar propriamente nas implicações ideológicas do problema, a relação com a publicidade propõe algumas questões de ordem prática importantes. É nesse sentido, aliás, que se lêem as palavras do poeta na mesma carta 42 , logo após a explicitação dos "dois neutralizadores da literatura": "lido o dia inteiro $\mathrm{c} /$ mensagens verdadeiras. quer dizer, mensagens q funcionam. / funcionam porq são maximalização de linguagens industriais. veiculadas certo, no lugar certo..."32

O trabalho com a publicidade (e a afirmação talvez se estenda também à própria canção popular) implica na elaboração de "mensagens que funcionam", ou seja, mensagens que percorrem plenamente o circuito comunicativo. $O$ que se lê, ao fundo do que fica explícito, é uma crítica às limitações comunicacionais da literatura, sobretudo do hermetismo experimental, que vem sendo posto em causa durante toda a carta em questão. Lê-se também um

31 São óbvias as contradições entre a valorização da linguagem publicitária sem restriçōes aqui e as críticas desenvolvidas anteriormente por Leminski na carta 42 ao aproximar a busca do novo pelo novo na experiência de vanguarda à dinâmica do mercado de bens de consumo. Igualmente, o neologismo "inutensílio", criado pelo poeta para conceituar o "poema", se choca com o utilitarismo a que a propaganda submete toda linguagem ( $C f$. o artigo "Inutensílio". In: LEMINSKI, Paulo. Anseios cripticos. Curitiba: Criar, 1986. p. 58-60.

32 Carta 42 , p. 120. 
SANDMANN, M. Nalgum lugar entre o experimentalismo...

confronto do livro com outros meios e tecnologias (jornal, televisão, rádio, disco, outdoor, etc. - "maximalização de linguagens industriais").

A eficácia da propaganda é medida em função de respostas muito precisas dadas pelo público a que se destina. Se o consumo de determinado produto aumenta em função de sua exposição por intermédio de uma mensagem publicitária, isso é índice suficiente para a aferição da eficácia da mensagem. Toda ela se articula em função do convencimento em relação à conveniência de se adquirir determinado produto, e este convencimento só parece ser possível se a comunicação é efetiva.

Concisão, coloquialismo, trocadilhos, neologismos, slogans, recursos visuais são ingredientes da poesia de Leminski que impregnam o universo da publicidade. É do deslocamento desses procedimentos do campo da propaganda para o da literatura que vai se alimentar em grande medida a sua arte. ${ }^{33}$

A música popular é outro dado importante, tanto pelo que pode haver de influência sobre a sua poesia, quanto pela experiência em si de Leminski na elaboração de canções.

$O$ apreço de Leminski por alguns compositores da canção popular brasilcira é grande. A esse respeito, pode-se ler o seguinte em trecho de entrevista concedida pelo poeta:

[...] na nossa geração o centro da poesia se deslocou do livro pra música popular. Com a geração que produziu Caetano e Chico Buarque, viu se deslocar o pólo da poesia, do suporte livro pro suporte disco. De repente os dois poetas da nova geração não cstão editando livros. São músicos que fazem letras e estão gravando discos. Realmente, não existe nenhum poeta escrito que você possa contrapor a Caetano e Chico na música popular. Com Cactano e Chico aconteceu uma coisa na música brasileira. Uma coisa muito grande, uma mudança de códigos. E isso prosseguiu. A associação entre poesia e música tende a se tornar cada vez maior em termos de Brasil. Os poetas mais bem dotados, mais talentosos vêm, pelo menos, prestando muita atenção na poesia dos letristas da música popular. ${ }^{34}$

33 Num certo sentido, o próprio concretismo, sobretudo no que diz respeito à trajetória de Décio Pignatari, é pioneiro na aproximação de literatura com a publicidade, o que, sob certa ótica, poderia indicar a dívida do poeta para com o movimento.

34 In: LEMINSKI, Anseios..., p. 28. No contexto de uma outra entrevista, Leminski 
Há uma série de questões embutidas nestas palavras.

Em primeiro lugar, Leminski diagnostica o grande prestígio da canção popular no Brasil, que, em sua geração, teria atraído definitivamente para o seu campo de ação a atenção de grandes artistas da palavra. Leminski diz, efetivamente, que Caetano Veloso e Chico Buarque são dois "poetas", os mais importantes da sua geração. Ao invés do livro, estariam usando o disco como suporte.

$\mathrm{Na}$ verdade, o trânsito entre canção popular e literatura por parte de alguns artistas da palavra, bem como as interinfluências entre as duas, é algo que não se restringe à geração de Leminski e vem de muito longe. Para citar um nome indiscutível, bastaria lembrar a trajetória de Vinicius de Morais, que adquire prestígio inicialmente pela poesia publicada em livro e vai migrando para o campo da canção, sobretudo a partir do final dos anos cinquienta, com sua colaboração como letrista com músicos da bossa nova. Mas o marco poderia ser situado mais para trás, com Orestes Barbosa, Catulo da Paixão Cearense, ou mais adiante ainda. ${ }^{35}$

Outro lance problemático é a aplicação do termo "poeta" de forma indistinta tanto para cancionistas como para aqueles que tradicionalmente recebem esta designação. A diferença entre os dois parece não se restringir somente ao "suporte" utilizado (ou livro ou disco, como sugere Leminski), mas a outros aspectos também, sejam formais, sejam pragmáticos - e, entre eles, o mais evidente, a articulação entre texto e música no caso da canção. ${ }^{36}$

De qualquer forma, o ponto básico aqui é o prestígio da canção popular no ambiente cultural brasileiro e sua ascendência decisiva sobre os poetas do livro. Vale ainda assinalar que Caetano Veloso e Chico Buarque, os dois nomes lembrados, diferentemente de Vinicius e outros, não são poetas que fazem

inclui ainda o nome de Gilberto Gil nesse rol: "Os três grandes poetas que a minha geração (tenho 40 anos agora) produziu são para mim Caetano Veloso, Gilberno Gil e Chico Buarque." (LEMINSKI, Paulo. Um escritor na biblioteca. Curitiba: Biblioteca Pública do Paraná, 1985. p. 23).

35 A respeito do trânsito de Catulo e Orestes Barbosa entre literatura e canção popular, bem como algumas reflexões gerais sobre o tema na cultura brasileira, $c f$. RODRIGUEZ, Benito Martinez. Luar da cidade, serião de neon: literatura e canção nas obras de Catulo da Paixão Cearense e Orestes Barbosa. São Paulo, 1998. Tese (Doutorado) - FFLCH, USP.

36 Parte substancial do trabalho acadêmico do compositor e professor Luiz Tatit é dedicado a discutir tais questões. Uma ótima abordagem da especificidade da canção em oposição à música, por um lado, e à poesia, por outro, se encontra em TATIT, Luiz. $O$ cancionista: composições de canções no Brasil, São Paulo: Edusp, 1996. 
SANDMANN, M. Nalgum lugar entre o experimentalismo...

canção, quer dizer, poetas que publicam poesia em livro e que também atuam como letristas. São cancionistas, no sentido forte e restrito do termo. ${ }^{37}$

\section{Operação mass-mídia}

As cartas de Leminski a Bonvicino testemunham alguns episódios da relação pessoal de Leminski com nomes importantes da música popular brasileira. Registram ainda o crescente interesse do poeta pela canção como gênero e seus esforços no sentido de tornar-se ele também, na esteira dos compositores que admira, um criador relevante no cenário da música popular.

Já na carta 1, pode-se ler o seguinte: "Mautner esteve a semana passada / estivemos juntos dois dias [...] esteve antes tom-zé / mas o papo não foi tão legal / por motivos vários / agora vem macalé / que já esteve este ano aqui / quando batemos um papão / a música popular do brasil crioulo está invadindo o sul / caetano/gil/doces bárbaros estiveram curtimos 4 dias incríveis / até cantei minhas músicas para eles imagine". 38

São todos nomes marcantes do movimento tropicalista e adjacências 39 que, em sua passagem pela cidade, incluem no roteiro um encontro obrigatório com o pocta curitibano. Fica clara a satisfação deste pelo interesse daqueles artistas por sua pessoa e por sua poesia. E é interessante notar o misto de timidez e orgulho da parte de Leminski quando relata ter mostrado algumas composições suas: "até cantei minhas músicas para eles imagine".

A aproximação de Leminski da música popular como compositor é relativamente tardia, como ele mesmo confessa em entrevista a Régis Bonvicino: "Em matéria de música popular, cheguei tarde na festa. Aprendi violão

37 Para uma definição mais precisa do termo "cancionista", $c f$. TATIT, $O$ cancionista..., cap.1, "Dicção do cancionista”, p. 9-27. Seria interessante sublinhar que quando Caetano e Chico, já consagrados como compositores populares, vão publicar livros de sua autoria, os gêneros escolhidos serã a prosa memorialística, no caso do primeiro, c o romance, no caso do segundo. A resistência a dedicar-se a uma produção de poesia em livro (stricto sensu) por parte dos autores e sua consagração, talvez mesmo ̀̀ sua revelia, como grandes "poetas" (lato sensu), parece ser bastante sugestiva de alguns dilemas e especificidades do ambiente cultural brasileiro neste final de século.

38 Carta 1, p. 31.

39 Explicitadamente: Jorge Mautner, Tom Zé, Jards Macalé, Caetano Veloso, Gilberto Gil. Doces Bárbaros é o nome do grupo formado pelos baianos Caetano Veloso, Gilberto Gil, Maria Bethânia e Gal Costa em meados dos anos 70, cuja turnê pelo Brasil se encontra registrada em disco homônimo e ao vivo de 1976. 
SANDMANN, M. Nalgum lugar entre o experimentalismo...

aos 26 anos. A máquina estava toda em andamento. Mas ainda deu para compor um pouco." 40

A despeito da interlocução com nomes fortes da música popular brasileira, Leminski compõe a princípio canções e letras para canções deslocado do eixo principal do show business e da indústria do disco no Brasil. Suas primeiras tentativas e colaborações com músicos curitibanos - com destaque para a parceria com Ivo Rodriguez, do grupo A Chave, grupo que será depois reformulado e rebatizado como Blindagem - só muito lentamente vão chegando ao público local, a princípio através de shows e, finalmente, com o registro em disco.

Na carta 14, sem data, escrita provavelmente entre o final de 1977 e início de 1978, lê-se o seguinte: "Sai agora o compacto (o 1..$^{\circ}$ ) da CHAVE com dois rockinhos maneiros letra minha: ME PROVOQUE PRA VER e BURACO NO CORAÇÃO (saindo vou aí levar)" ${ }^{\prime 1}$. Seria pertinente lembrar das dificuldades de se chegar naquela época ao disco, mesmo ao formato do simples compacto, sem se estar sediado no Rio de Janeiro ou em São Paulo e sem vínculos pertinentes com alguma grande gravadora.

Mais adiante, na carta 21 , de 13 de abril de 1978, outro episódio da trajetória musical curitibana de Leminski merece registro: "censura vetou 'verdura', a única das minhas/nossas canções q engatou: ivo faz show sozinho nome do show IVO, no teatrinho da passagem: só músicas nossas: só com o violão de 12 e a gaitinha (daqui um mês, VENHA!)". 42

"Verdura", letra e música escritas por Leminski, seria gravada em 1981 pelo grupo Blindagem, em LP do mesmo nome, junto com várias outras canções com letras suas. Em carta de abril de 1981 (carta 66), por ocasião da gravação do disco, Leminski dirá: "já quanto ao ivo, tenho certeza que gravou um LP com a "blindagem", uma banda de gatos brabos de terreno baldio daqui, que o acompanha, fielmente, como um cão sem dono, gente guitarreira, zoenta, punk, jóia do repertório qualquer coisa. 8 letras minhas com ivo, inclusive 'que eu sou legal eu sei', que a censura só liberou agora ('que loucura', nossa, já gravada, tá retida em brasília, por causa do verso 'e traga os bandidos')."

40 LEMINSKI, Paulo. Paulo Leminski desconta tudo. GAM, Rio de Janeiro, 1976. Entrevista. Republicada em Envie meu dicionário..., p. 205-211.

41 Carta 14, p. 59.

42 Carta 21, p. 67.

43 Carta 66, p. 171. O interesse de Leminski pelo rock recebe a seguinte formulação na entrevista a Régis Bonvicino já referida neste ensaio: "O rock me interessou, quando me interessei 
SANDMANN, M. Nalgum lugar entre o experimentalismo...

Mas a canção "Verdura" seria registrada também por Caetano Veloso, no mesmo ano, no LP Outras palavras, lançando nacionalmente o nome de Leminski como compositor popular.

A interlocução musical com Caetano Veloso é das mais estimulantes para o poeta. Na carta 53, por exemplo, de 14 de setembro de 1979, Leminski escrevia: "Gil esteve aqui. Cae está. / Cantei a maior parte das músicas pra ele (estive com ele os 3 dias) / ele desbundou! leva duas fitas com 13 músicas. / disse q vai cantar TUDO. vai gravar, seu próximo LP vai ser $1 / 2 \mathrm{com} /$ música de amigos". ${ }^{44}$ Depois de referir-se a algumas canções que teriam especialmente chamado a atenção de Caetano Veloso, Leminski acrescenta: "disse q se eu fazia músicas para amigos, / agora, estou pronto para estourar (palavras textuais dele). / dei uma letra também / q ele disse na hora q vai musicar. / aguardo."45

É mais do que óbvio o entusiasmo que cerca esta boa acolhida. Na carta 55, sem data, mas provavelmente escrita ainda nesse mesmo ano, Leminski registra uma nova passagem de Gilberto Gil pela cidade, em que o compositor teria dedicado a ele a canção "Logunedé", durante show, nos seguintes termos: "para Paulo Leminski, grande poeta do Paraná, poeta realce, uma das inteligências mais faiscantes deste país...". 46

Com a chancela destes seus ídolos, e com o crescente interesse de outros artistas pela sua produção musical, Leminski desabafa mais adiante: "Estou até meio tonto com tanto... / $\mathrm{E}$ um sonho paranóico de 10 anos come true!" "47 E na conclusão da carta: "minha passagem para a MPB está para se completar: operação mass-mídia". ${ }^{48}$

por contracultura./É colonizado, massificado, comercial, alienante e alienado./ Por isso.acho que no rock as contradições do capitalismo saltam aos ouvidos. / Rock é chicletes. É modess. É lanchonete. / É barato. É consciência elétrica. Indústria. Big business. Em inlês. / Quando entrei emcontato mais íntimo com o planta A CHAVE já compunha. Juntamos repertório e muitos rocks nasceram. / Mas quero registrar que me interessam todos os ritmos. De Cartola a Walter Franco. Do bolero ao baião, do tango ao mambo, até o silêncio." (In: Envie meu dicionário..., p. 210-211).

44 Carta 53, p. 151-152.

45 Carta 53, p. 152.

46 Carta 55, p. 155.

47 Carta 55, p. 155.

48 Carta 55, p. 156. 
SANDMANN, M. Nalgum lugar entre o experimentalismo...

\section{Curitiba no mapa da poesia}

As cartas contidas em Envie meu dicionário documentam as preocupações artísticas e o dia-a-dia do escritor Paulo Leminski justamente no momento em que sua produção está prestes a se tornar mais amplamente conhecida. Captam o poeta na iminência de sair do relativo anonimato curitibano em direção a uma popularidade dentro do círculo dos leitores de poesia e literatura no Brasil que se mantém viva até hoje. Explicitam ainda os dilemas poéticos enfrentados por Leminski na tentativa de lidar com elementos dificilmente conciliáveis como "experimentação" e "comunicação", "informação culta" e "cultura popular e de massa". Leminski percorreu, com alguns sobressaltos, o contraditório caminho que leva da vanguarda experimental à canção popular. Radicou sua própria poesia mais pessoal nalgum lugar entre esses dois termos.

Agora neste ano de 1999, nas homenagens locais ao poeta pelos dez anos de sua morte, entre os depoimentos sempre altamente envolvidos de amigos e entusiastas, dois artigos de intelectuais sediados em Curitiba vêm pôr em discussão a imagem sedimentada do poeta: "Literatura e publicidade", do artista plástico e escritor Carlos Dala Stella, de intenção polêmica e corrosiva, e "Poeta da sensibilidade adolescente", do crítico de literatura e também escritor Miguel Sanches Neto, sentencioso, conciliador e abrangente. ${ }^{49}$

Sem querer retomar aqui na íntegra as ricas e contundentes postulações dos dois textos, de um modo geral distintas entre si em muitos aspectos, vale registrar que ambos confluem no que diz respeito a um ponto julgado como decisivo na personalidade literária de Paulo Leminski: a sua (nas palavras de Sanches) "sensibilidade adolescente". Haveria algo de inacabado, imaturo, juvenil na produção de Leminski, a que lances vitalistas, narcisistas e auto-promocionais como agitador e iconoclasta viriam se somar, tornando-o especialmente atraente para os leitores mais jovens. Este, ao mesmo tempo, seria também o limite maior da sua produção, diante da qual leitores mais exigentes e maduros não revelariam igual entusiasmo.

Paulo Leminski morreu um pouco antes de completar 45 anos de idade. Sua projeção no cenário da cultura nacional, quando canções suas são gravadas

49 DALA STElla, Carlos. Literatura e publicidade. Gazeta do Povo, Curitiba, 6 jun. 1999. Cademo G, p. 8. SANCHES NETO, Miguel. Poeta da sensibilidade adolescente. Gazeta do Povo, Curitiba, 7 jun. 1999. Caderno G, p. 8. No Caderno G de 6 de junho 1999, há uma série de depoimentos de escritores e outros artistas curitibanos sobre Paulo Leminski. 
SANDMANN, M. Nalgum lugar entre o experimentalismo...

por estrelas da MPB e trabalhos seus editados pela Brasiliense, começou a se dar mais ou menos 10 anos antes, no início da década de 80 , portanto quando ele tinha cerca de 35 anos. Não deixa de ser curioso e sinal dos tempos que dois intelectuais que ainda não atingiram a idade que Leminski tinha quando morreu avaliem sua obra como insuficiente para as questões estéticas e existenciais da maturidade.

Da minha parte, o interesse pela "personalidade literária" de Paulo Leminski - essa somatória de vida e obra - se deve em grande medida ao vigor da sua intervenção, que logrou romper o véu de insignificância cultural que, com breves instantes de exceção, longamente tem pairado sobre Curitiba. Paulo Leminski colocou a cidade no mapa da poesia brasileira a partir de uma interlocução com nomes fortes da literatura e da música popular que ecoa ainda hoje. Se pelas virtudes de sua obra em si, se pelo seu temperamento expansivo e carisma pessoal, se por mero acaso ou por senso de oportunidade, ou se por uma combinatória de todos esses elementos, o fato é que o papel desempenhado por Leminski é vital para a consciência local. Ler as cartas contidas em Envie meu dicionário, a partir de Curitiba, é deixar-se impregnar por uma energia de vida e uma abertura de perspectivas que poucos criadores (aqui e fora) têm conseguido irradiar.

\section{RESUMO}

O presente artigo aborda Envie meu dicionário, a nova e agora completa edição das cartas escritas pelo poeta curitibano Paulo Leminski a Régis Bonvicino entre 1976 e 1981. O período em questão antecede justamente o momento em que Leminski desponta no cenário nacional como grande revelação da jovem poesia brasileira de então. As cartas documentam as diversas preocupações de Leminski como criador. Procurou-se destacar neste estudo o trânsito do escritor da experimentação literária e do vínculo com o concretismo em direção a uma poesia mais comunicativa e à canção popular.

Palavras-chave: Paulo Leminski, Régis Bonvicino, epistolografia. 
SANDMANN, M. Nalgum lugar entre o experimentalismo...

\section{ABSTRACT}

This paper examines Envie meu dicionário, the new and now complete edition of letters written by Paulo Leminski - a poet from Curitiba - to Régis Bonvicino between 1976 and 1981 . This is the time period which precedes Leminski's emergence as a major young poet in the Brazilian literary scene. The letters provide a clear expression of the various concerns Leminski had as an artist. More specifically, this study focuses on his trajectory from literary experimentation and concrete poetry in the direction of more communicative poetry and popular music.

Key-words: Paulo Leminski, Régis Bonvicino, epistolary writing

\section{REFERÊNCIAS}

CAMPOS, Augusto de et al. Balanf̧o da bossa e outras bossas. 3. ed. São Paulo: Perspectiva, 1978.

. Teoria da poesia concreta: textos críticos e manifestos: 1950-1960. 3. ed. São

Paulo: Brasiliense, 1987.

CAMPOS, Haroldo de. Uma leminskíada barrocodélica. Folha de São Paulo, 2 set. 1989.

DALA STELLA, Carlos. Literatura e publicidade. Gazeta do Povo, Curitiba, 6 jun. 1999.

Caderno G, p. 8.

LEMINSKI, Paulo. Anseios cripticos. Curitiba: Criar, 1986. . Catatau. 2. ed. Porto Alegre: Sulina, 1989.

- Envie meu dicionário: cartas e alguma crítica. Organização de Régis Bonvin-

ciano, com a colaboração de Tarso M. de Melo. São Paulo: 34, 1999.

. Paulo Leminski. Série Paranaenses, n. 2. Curitiba: Scientia et Labor, 1988.

. Um escritor na biblioteca. Curitiba: Biblioteca Pública do Paraná, 1985.

MELO, Tarso M. de. Qualigrafeira. Viola de Cocho, abr./maio 1998. (Texto também disponível na Internet em página dedicada a Paulo Leminski: http://users.sti.com.br/efres/leminski/kamiquase.htm)

POUND, Ezra. Abc da literatura. Trad. por Augusto de Campos e José Paulo Paes. São Paulo: Cultrix, [s.d.].

RODRIGUEZ, Benito Martinez. Luar da cidade, sertão de neon: literatura e canção nas obras de Catulo da Paixão Cearense e Orestes Barbosa. São Paulo, 1998. Tese (Doutorado) - FFLCH, USP.

SANCHES NETO, Miguel. Poeta da sensibilidade adolescente. Gazeta do Povo, Curitiba, 7 jun. 1999. Caderno G, p. 8.

SUZUKI, D. T. Introdução ao zen-budismo. Trad. por Murillo Nunes de Azevedo. São Paulo: Pensamento, [s.d].

TATIT, Luiz. O cancionista: composição de canções no Brasil. São Paulo: Edusp, 1996. 